IDAHO NATIONAL ENGINEERING LABORATORY

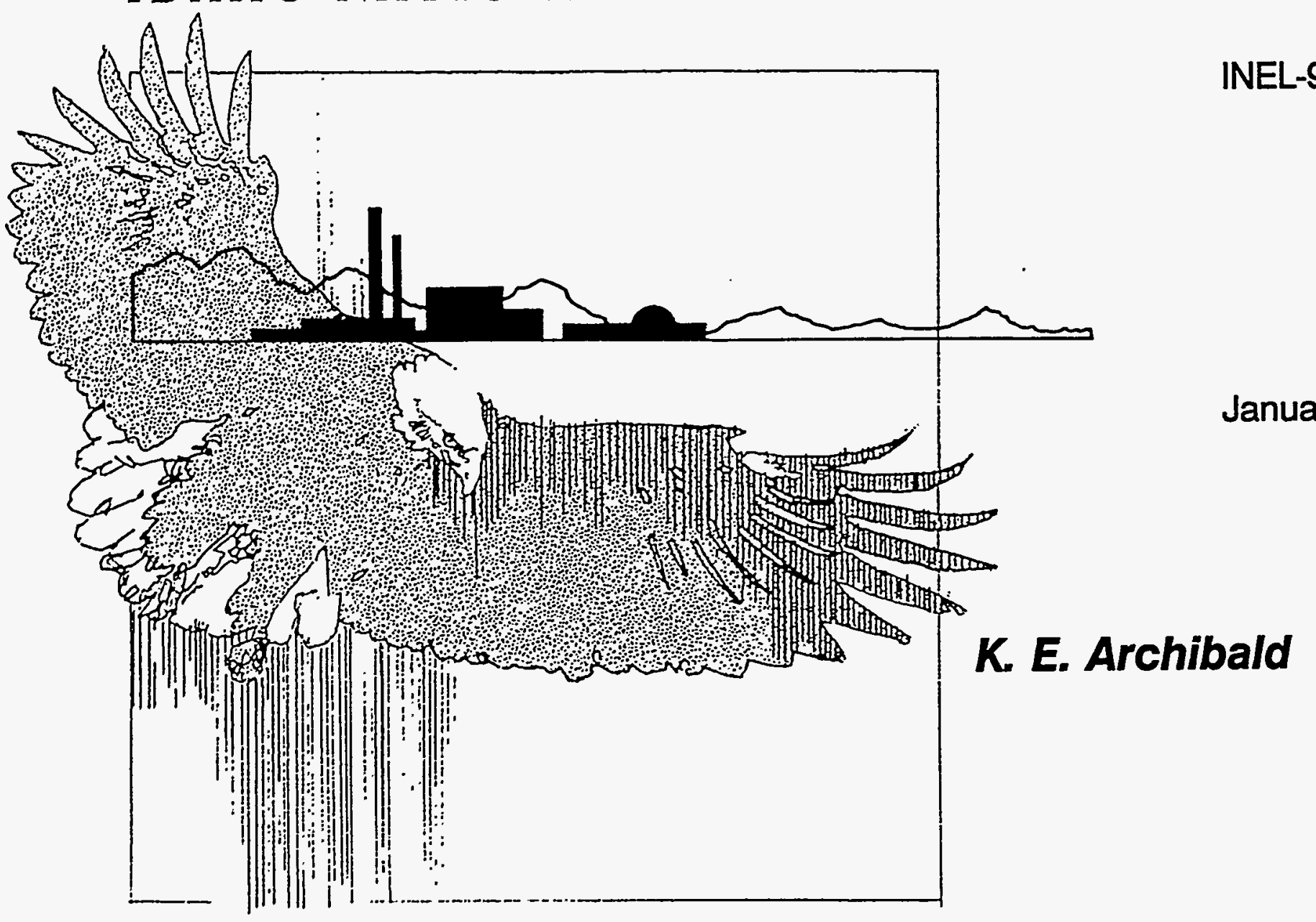

\title{
Concrete Decontamination Scoping Tests
}

Idaho National Engineering Laboratory 


\section{DISCLAIMER}

This report was prepared as an account of work sponsored by an agency of the United States Government. Neither the United States Government nor any agency thereof, nor any of their employees, makes any warranty, express or implied, or assumes any legal liability or responsibility for the accuracy, completeness, or usefulness of any information, apparatus, product or process disclosed, or represents that its use would not infringe privately owned rights. References herein to any specific commercial product, process, or service by trade name, trademark, manufacturer, or othenwise, does not necessarily constitute or imply its endorsement, recommendation, or favoring by the United States Government or any agency thereof. The views and opinions of authors expressed herein do not necessarily state or reflect those of the United States Government or any agency thereof. 


\title{
Concrete Decontamination Scoping Tests
}

\author{
K. E. Archibald
}

Published January 1995

Idaho National Engineering Laboratory

Lockheed Idaho Technologies Company

Idaho Falls, Idaho $\mathbf{8 3 4 1 5}$

Prepared for the

U.S. Department of Energy

Under DOE Idaho Operations Office

Contract DE-AC07-94ID13223 


\section{DISCLAIMER}

Portions of this document may be illegible in electronic image products. Images are produced from the best available original document. 


\section{ABSTRACT}

This report details the research efforts and scoping tests performed at the Idaho Chemical Process Plant using scabbling, chemical, and electro-osmotic decontamination techniques on radiologically contaminated concrete. 
(1) 


\section{CONTENTS}

ABSTRACT $\ldots \ldots \ldots \ldots \ldots \ldots \ldots \ldots \ldots \ldots \ldots \ldots \ldots \ldots \ldots \ldots \ldots \ldots \ldots \ldots \ldots$

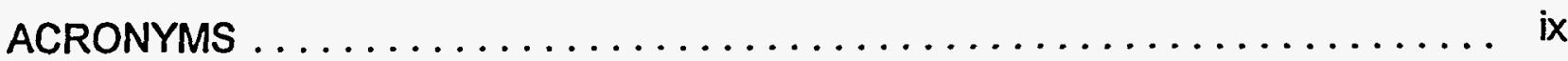

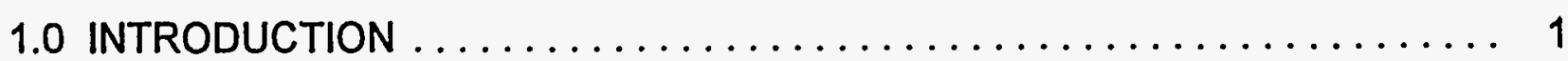

2.0 TESTING PROCEDURE $\ldots \ldots \ldots \ldots \ldots \ldots \ldots \ldots \ldots \ldots \ldots \ldots$

3.0 SCABBLING TECHNIQUE $\ldots \ldots \ldots \ldots \ldots \ldots \ldots \ldots \ldots \ldots \ldots \ldots \ldots$

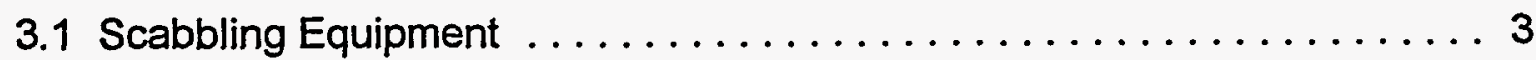

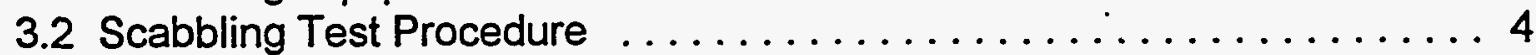

3.3 Scabbling Results $\ldots \ldots \ldots \ldots \ldots \ldots \ldots \ldots \ldots \ldots \ldots$

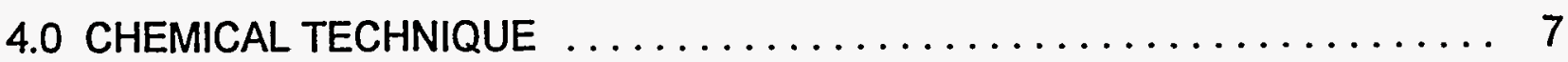

4.1 Chemical Equipment $\ldots \ldots \ldots \ldots \ldots \ldots \ldots \ldots \ldots \ldots \ldots$

4.2 Chemical Test Procedure $\ldots \ldots \ldots \ldots \ldots \ldots \ldots \ldots \ldots$

4.3 Chemical Results $\ldots \ldots \ldots \ldots \ldots \ldots \ldots \ldots \ldots \ldots$

5.0 ELECTRO-OSMOTIC PULSE TECHNOLOGY $\ldots \ldots \ldots \ldots \ldots \ldots \ldots \ldots$

5.1 Electro-Osmotic Pulse Equipment $\ldots \ldots \ldots \ldots \ldots \ldots \ldots \ldots \ldots \ldots \ldots$

5.2 Electro-Osmotic Pulse Test Procedure . . . . . . . . . . . . . 11

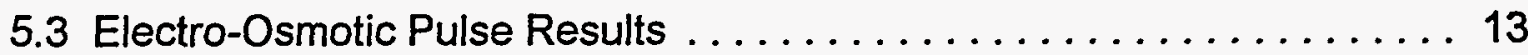

6.0 RECOMMENDATIONS/CONCLUSIONS $\ldots \ldots \ldots \ldots \ldots \ldots \ldots \ldots$

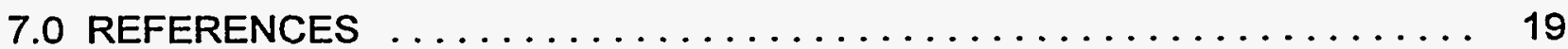

\section{FIGURES}

1. Pentek System .................................. 5

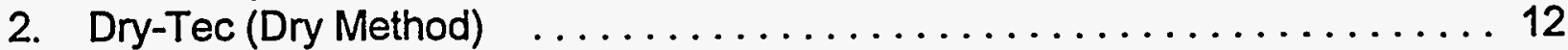

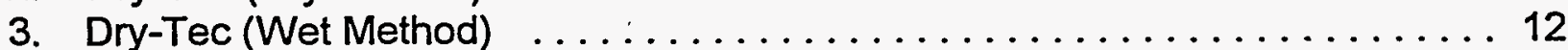

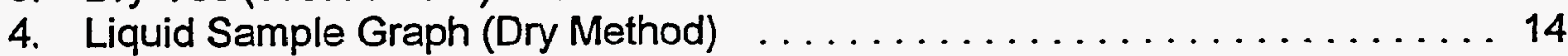

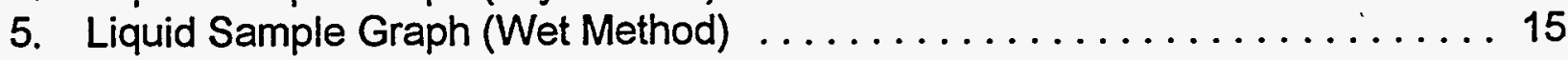




\section{TABLES}

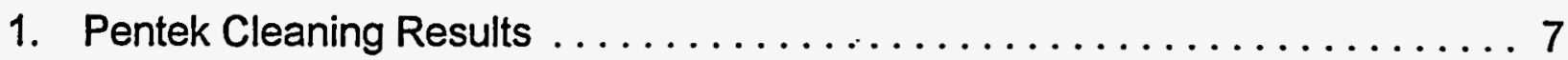

2. EET Cleaning Results ............................ 10

3. Dry-Tec (Wet Method) Results ...................... 16

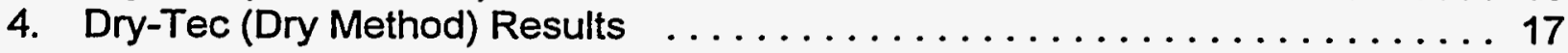

5. Dry-Tec Results From Pans and Cathodes $\ldots \ldots \ldots \ldots \ldots \ldots \ldots \ldots$ 


\section{ACRONYMS}

CAM Constant Air Monitor

EET Environmental Extraction Technologies

HEPA High Efficiency Particulate Air

INEL Idaho National Engineering Laboratory

ICPP Idaho Chemical Processing Plant

RFP Request for Proposal 


\section{Concrete Decontamination Scoping Tests}

\subsection{INTRODUCTION}

Past concrete decontamination efforts at the Idaho Chemical Processing Plant (ICPP) involved washing concrete with high pressure water or chemicals. This produced large amounts of radioactively contaminated sodium-bearing liquid waste or secondary waste. Another method crushed the concrete resulting in high volumes of contaminated solid waste. With the curtailment of reprocessing at the ICPP, the focus of decontamination is shifting from maintenance for continued facility operation to decommissioning. Decommissioning plans need to include alternate concrete decontamination methods with higher decontamination factors, increased flexibility, lower personnel exposure, and decreased amounts of secondary liquid waste generation.

The methods chosen for the 1994 concrete decontamination scoping studies were 1) scabbling (a proven technique), 2) a new chemical process, and 3) an experimental technique called electro-osmotic pulse technology. This report details the research and scoping tests completed on these three techniques.

\subsection{TESTING PROCEDURE}

Three techniques were tested and evaluated at the ICPP using concrete containing radioactive contamination common to the Idaho National Engineering Laboratory and throughout the Department of Energy complex. During the demonstrations, tests were performed to evaluate the techniques for flexibility, operability/simplicity, waste generation, and decontamination factors.

A Commerce Business Daily (CBD) announcement was published requesting information from commercial parties interested in performing a demonstration using proven and new concrete decontamination techniques. After compiling and evaluating responses from the CBD announcement, a request for proposals (RFP) was published. The RFP contained criteria which included: amount of radioactively contaminated concrete to clean, maximum 55 gallons liquid waste generation, no toxic chemicals, and no airborne contamination. A run plan and pre-operational checklist was also written and approved for this demonstration Three companies met the criteria detailed in the RFP. Subcontracts were awarded to 1) Pentek from Coraopolis, Pennsylvania (scabbling), 2) Environmental Extraction Technologies (EET, Inc.) from Houston, Texas (chemical), and 3) Dry-Tec from Huntsville, Alabama (electro-osmotic pulse technology).

Three separate demonstrations were conducted. Each company was required to clean approximately $24 \mathrm{ft}^{2}$ of radioactively contaminated concrete. The concrete lids used in the demonstrations had covered a settling basin. The basin had been filled with radioactively contaminated water and left in place for 20-25 years. The liquid inside the basin had risen 
approximately 2-3 inches above the bottom of the lid. Radiological contamination in the water consisted primarily of cesium, with lessor amounts of uranium, plutonium, strontium, cerium, cobalt, europium, and americium.

Each lid was moved into a tent ( $12^{\prime}$ wide $\times 22^{\prime}$ long by $8^{\prime}$ high), which was divided into two compartments. The work was performed in one compartment while the other compartment contained a Constant Air Monitor (CAM) and was used as a step-off area. To help control airborne activity a $1500 \mathrm{cfm}$ blower was connected to the first compartment. The $1500 \mathrm{cfm}$ HEPA blower was located outside the tent area. Each compartment had observation windows.

As a lid was moved into the tent, it was turned over and placed on a wooden pallet to expose the bottom of the lid. This was the most heavily contaminated area of the lid. Each lid was approximately 4" thick and had one matrix of rebar located in the middle. The surface of each lid was smooth without visual cracks. However, the lids had been core sampled before they were removed from the settling basin. The concrete was standard 3000 psi concrete.

Core samples were taken on the lids that were used for the chemical and electro-osmotic techniques before and after each of these demonstrations. The cores were taken with a $5 / 8^{\prime \prime}$ drill bit and a drill. The core taking technique used during this demonstration involved capturing the concrete dust at different depths using the same core hole. When the drill bit reached depths of 3/4", 1-3/4" and 2-3/4" the drilling was stopped and the dust was collected. The drill bit was cleaned after each depth was reached.

Each company was given 7 to 10 days to perform their concrete decontamination demonstration. During testing, decontamination technique data were taken on the operability/simplicity, flexibility, decontamination factors, cleaning time, and waste generation. One of the major testing goals was to determine if each technique could clean the concrete lid to the ICPP free release standards. The free release criteria is as follows:

1) $<200 \mathrm{dpm}$ Beta/Gamma (smearable)

2) <10 Alpha dpm (smearable)

3) $\quad<100 \mathrm{cpm}>$ background Beta/Gamma (fixed)

4) No detectable Alpha (fixed) 


\subsection{SCABBLING TECHNIQUE}

When researching concrete decontamination techniques, scabbling appeared to be the "standard" method to compare against. Scabbling is a process which removes surface layers to remove contamination from metal or concrete surfaces. This method has been around a long period of time and has proven very effective. However, in certain situations this method is not the most viable technique. Scabbling involves removing layers of concrete by means of pneumatically operated needles or bits, water jets, shot blasting, grit blasting, grinding, honing, scraping, hand brushing, or automated brushing. The majority of these techniques minimize the amount of secondary waste that is generated but are very labor intensive.

Pentek Inc. used the scabbling method during their concrete decontamination demonstration. A wide variety of scabblers both hand held and remotely operated are currently available that can be used depending on the conditions and location of the area to be cleaned. The most commonly used scabblers have pneumatically operated pistons or needles that simultaneously strike the surface of the concrete or metal, causing a chipping effect to remove the contamination or surface layers of concrete. The scabbling bits are located on the pistons. The number and size of scabbling bits can be varied along with the number, size, and type of needles, depending on how much surface removal or reduction is needed. The size, type, and number of bits or needles can effect the speed of removal or reduction of the surface being cleaned.

\subsection{Scabbling Equipment}

The integrated vacuum system used during the concrete scabbling decontamination demonstration at ICPP was a Pentek VAC-PAC model 9 . This was an air powered system which used 9 venturies which were located on the top of the HEPA filters for air flow. The system air consumption at 85 psi was $105 \mathrm{scfm}$. A $120 \mathrm{~V}$ electrical outlet was required. The needle gun used in the demonstration was a pneumatic, piston-driven corner-cutter with $3 \mathrm{~mm}$ reciprocating needles. The needle gun was designed to remove contamination from outside edges and inside corners of steel and concrete surfaces. The tool was a hand held apparatus equipped with a 1-1/2 inch vacuum hose connection to the end of the gun to collect the dust and debris as it was removed from the surface and delivered to the VAC-PAC system. The needle gun had different sizes of hardened steel needles $(3 \mathrm{~mm}$, $4 \mathrm{~mm}$, and $2 \mathrm{~mm}$ ) which could easily be changed out. The $3 \mathrm{~mm}$ and $4 \mathrm{~mm}$ needles were designed to clean and remove concrete surfaces. The $2 \mathrm{~mm}$ needles were designed to clean steel surfaces. Special copper-beryllium needles that are designed to prevent sparks may be purchased. The corner-cutter has adjustable shrouds that conform to all surface types. The needle gun was ergonomically designed with a pivoting vacuum head for work in difficult areas. It had a cutting width of 1-3/4 inches, had a gun length of 14 inches and it weighed 9 pounds.

A pneumatically operated squirrel-III' scabbler was also used in the demonstration. The scabbler had 3, 1-3/4 inch diameter, 9 point tungsten-carbide tipped bits. The system was 
designed to remove coated and uncoated concrete surfaces at $1 / 16^{\prime \prime}$ per pass. The squirrel-III was a manually operated system designed with vibration isolation elements to help direct vibrations away from the operator. The system had no rotating parts which helped prevent the internal parts from becoming contaminated. The squirrel-III was designed for small decontamination jobs on concrete floors. The main working area of the squirrel is 6 inches and it can be moved to within $1 / 2$ inch of a wall. This system used a brush shroud. The squirrel also had a 1-1/2 inch vacuum hose to collect the debris and dust as it was removed from the surface and then delivered to the VAC-PAC system. This system looks similar to a system that is used to wax floors. The squirrel-IIl had a width of 6 inches, a height of 12 inches, and a length of 12 inches, and it weighted 50 pounds.

The VAC-PAC model 9 system can run a maximum of 4 corner-cutters up to 100 feet. A combination of corner-cutters and squirrels can also be used. When increasing the distance from the work location, the number of tools that can be operated decreases to 1 corner cutter at 200 feet; larger VAC-PAC systems are available either for more tools and/or greater distances.

This VAC-PAC system was dustless. The dust and debris created by the cornercutter/needle scalers and squirrel scabblers was captured by shrouds covering the tool surface and then transported through a vacuum hose by a VAC-PAC HEPA filtered vacuum and waste packaging system. The portable VAC-PAC system had two stages of filters. The first stage of filters was located in the plenum and were self-cleaning prefilters, cleaned by reverse-flow pulses of high pressure air. The second stage of filters were HEPA filters located at the top of the VAC-PAC system. The VAC-PAC system also had a patented drum change-out method. The debris and dust were transported to the VACPAC system and were then deposited into standard 55 or 23 gallon waste drums. This VAC-PAC system allowed the person operating the system to fill, seal, remove, and replace full drums with empty drums under vacuum conditions. Pentek's change-out system eliminated the possibility of spreading contamination while changing waste drums. The VAC-PAC system also had a level indicator that was lowered into the drum and automatically alarmed when the drum was full. The dimensions of the VAC-PAC system are 4 feet long $\times 4.3$ feet wide $\times 6$ feet high.

\subsection{Scabbling Test Procedure}

The concrete lid used during this demonstration was moved into the tent and placed on a wooden pallet. The general layout of the scabbling equipment is depicted in Figure 1. All scabbling equipment, except the VAC-PAC, was located inside the tent with the lids. The vacuum and air supply hoses ran into the tent from the outside. The air supply came from the plant air supply, approximately 200 feet from the demonstration tent. The pressure gauge on the VAC-PAC read 85 psi when the plant air supply was turned on. $A$ standard 55 gallon waste drum was used.

At the start of the test, the squirrel-1II scabbler was lifted approximately 8 inches off the floor and placed on top of the concrete lid. Once started, the squirrel scabbler was easy to control. There did not appear to be any vibration during operation of the squirrel; any 


\section{Figure $\# \mathbb{N}=\mathbb{P E N T E} \mathbb{K}$ System}

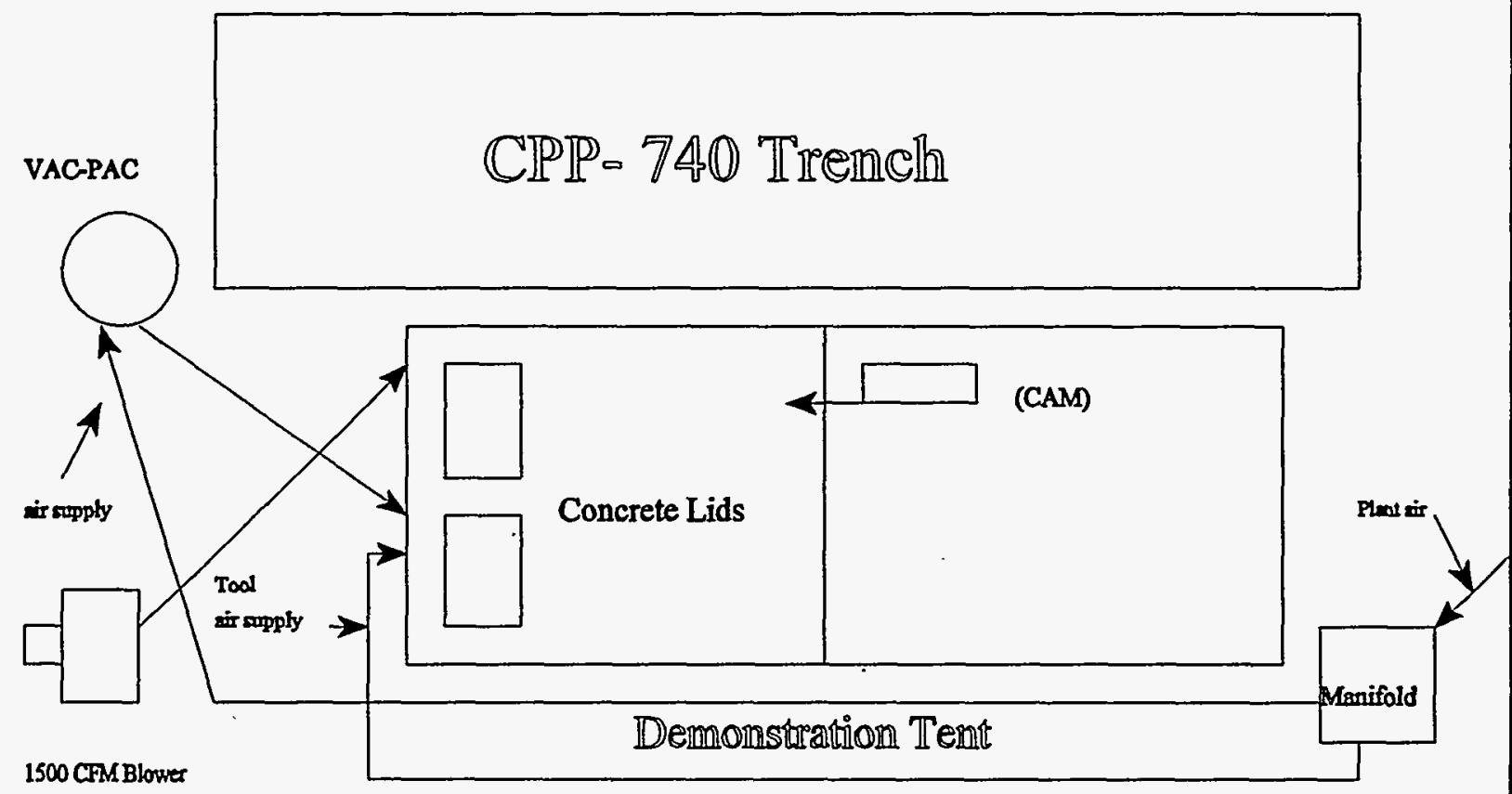

Figure 1: Layout of Pentek System

vibration apparently had been absorbed by the vibration bar on the squirrel. Surface layers were removed by starting at a corner of the lid and slowly moving the squirrel in a circular motion until $1 / 8$ inch was removed. After the corner was scabbled, the squirrel was moved to another spot on the lid were the technique was repeated. In order to keep the dust and debris from becoming airborne, the squirrel was started approximately 2 inches from the edge of the concrete lid. The only problem encountered during this process was moving the vacuum and air supply hoses. The work area was so small that the operator could not easily move around the lid. During this process, no dust was noticed around the shroud. The CAM, located inside the tent, did not register any radioactive airborne particulate while the scabbling was taking place. It was important to note that during the drum change-out the VAC-PAC system was moved into the tent. No radioactive airborne activity was registered on the CAM while the drum was being changed out.

After the entire surface of the lid had been scabbled to $1 / 8$ inch deep, a 2 inch strip of concrete remained around the edge of the lid. The needle gun was used to remove the strip. The needle gun seemed to be a bit labor intensive but extremely easy to use. A flat surface shroud was placed on the needle gun and the scabbling continued until the 2 inch strip of concrete was removed to a depth of $1 / 8$ inch. No dust was noticed around the 
shroud when the needle gun was being used. During the use of the needle gun, no airborne contamination was indicated on the CAM.

\subsection{Scabbling Results}

While the VAC-PAC system was operating, contact radiological readings were taken on the waste drum and vacuum hose from outside the tent. As the dust and particles traveled up the vacuum hose, the instrument readings would rise. The initial contact reading at the plastic window of the tent, located approximately 3 to 4 inches from lid, was $10 \mathrm{mr} / \mathrm{hr}$ betalgamma. The initial contact reading on the surface of the waste drum was $2 \mathrm{mr} / \mathrm{hr}$ beta/gamma. Once 1/8 inch of the concrete surface had been removed by the squirrel, the reading at the window was $4 \mathrm{mr} / \mathrm{hr}$ beta/gamma and $10 \mathrm{mr} / \mathrm{hr}$ beta/gamma at the waste drum.

The entire system was very flexible and easy to operate. The system generated very little waste; the lid surface after cleaning was level and did not have any peaks or valleys.

The total time required to remove $1 / 8$ inch of concrete surface from the entire lid was approximately 56 minutes. The squirrel was used 36 minutes and the needle gun was used approximately 20 minutes. The needle gun was operated by a LITCO technician with no previous scabbler operating experience. The cleaning results from this test are depicted in Table 1. After cleaning, the lid was divided into 4 areas for radiological surveys. These results indicated scabbling is a good technique for removal of surface contamination on concrete. A second layer could be removed to reduce levels further. If contamination has soaked into the concrete very far and structural integrity is a concern, this might not be a good technique to use for cleaning. Both the squirrel and corner-cutter remove $1 / 16$ " of concrete surface per pass. Some work has been done on making a system that can be operated remotely. Recontamination was not a problem with the system because of the collection system. To fill a 55 gallon drum, $700 \mathrm{ft}^{2}$ of concrete surface would have to be scabbled to a depth of $1 / 16^{\prime \prime}$. After the demonstration was complete, the equipment was decontaminated and $90 \%$ of the equipment was returned to the vendor. Two Pentek systems were purchased for the ICPP. A VAC-PAC model 9 and model 12 with accessories were purchased for future use at the ICPP for a cost of approximately $\$ 90,000$. 
TABLE 1

PENTEK Concrete Cleaning Results At ICPP

\begin{tabular}{|c|c|c|c|c|c|}
\hline \%.: & $1 \%$ \%ONHAY & Q & 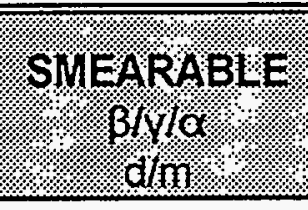 & 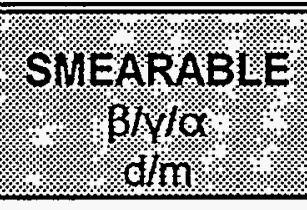 & \% Reduction \\
\hline & BEFORE & AFTER & BEFORE & AFTER & \\
\hline$\# 1$ & 150 & 10 & $\begin{array}{c}42,520 \beta \gamma \gamma \\
184 \alpha\end{array}$ & N/A & $\begin{array}{c}93.3 \% \\
\text { (Contact) }\end{array}$ \\
\hline \# 1 (Area \#1) & N/A & N/A & N/A & $\begin{array}{l}400 \beta / \gamma \\
<10 \alpha\end{array}$ & \multirow{4}{*}{$\begin{array}{c}\text { Over all } \\
\text { Smearable } \\
\\
93.9 \% \beta / Y \\
47.8 \% \alpha \\
\text { (Based on highest } \\
\text { reading) }\end{array}$} \\
\hline$\# 1$ (Area \#2) & N/A & $N / A$ & N/A & $\begin{array}{c}1112 \beta / Y \\
<10 \alpha \\
\end{array}$ & \\
\hline$\# 1$ (Area \#3) & $N / A$ & N/A & N/A & $\begin{array}{c}2576 \beta / \gamma \\
48 \alpha \\
\end{array}$ & \\
\hline$\# 1$ (Area \#4) & N/A & N/A & N/A & $\begin{array}{c}2576 \beta / Y \\
48 \alpha\end{array}$ & \\
\hline
\end{tabular}

${ }^{\star} \mathrm{N} / \mathrm{A}=$ Not Available.

\subsection{CHEMICAL TECHNIQUE}

Chemical concrete decontamination techniques have also proven to be effective, but tend to create large amounts of secondary waste. The use of chemicals is limited by penetration depth and can actually drive contamination deeper into the concrete'. The chemicals that are currently being used (acids, detergents) are mostly used for the removal of surface contamination.

Environmental Extraction Technologies (EET, Inc.) conducted the chemical portion of the concrete decontamination demonstration using their "TECHXTRACT" contamination extraction technology. This technology has been used to remove a variety of contaminants; PCB's, heavy metals, radionuclides, and RCRA organics from concrete, steel, brick, and other materials from porous materials and underlying substrates. The chemicals used by EET to clean concrete claim to have an advantage over standard chemicals in that they only use a small amount of chemical which penetrates the surface and draws the contamination to the concrete surface to be captured. The chemicals and detergents normally used at the ICPP create large quantities of secondary waste and remove surface contamination only. The chemicals used in EET's process will not damage the surface or substrate. 


\subsection{Chemical Equipment}

EET's equipment consisted of scrub brushes, three five gallon plastic containers of chemicals (each with a different chemical), a HEPA vacuum, and 5 gallons of demineralized water. The chemicals are proprietary and will be referenced as chemical 100,200 , and 300 . For ease of application, each chemical was transferred into plastic spray bottles before being taken into the work area. Floor scrubbers (standard janitorial rotating disk equipment) are used to scrub the chemicals into the surface of the concrete when this technique is being used on large surface areas.

\subsection{Chemical Test Procedure}

The concrete lid used during the demonstration was moved into the tent and placed on a wooden pallet which was located inside a drip pan. One survey was taken before the demonstration was started and one after each chemical application. Two core samples were taken in opposite corners of the lid before cleaning and two after cleaning. Surveys which consisted of taking one smear of the entire lid surface were taken on the lid before and after each chemical application. Contact readings were also taken on the lid before and after the demonstration. All of the equipment, except for the HEPA vacuum, was located inside the tent.

A small hole exposing the rebar matrix was noted when the lid was unwrapped. The hole in the concrete was caused by a core sample that had been taken before the lid was removed from the trench. The remaining surface of the concrete was free from cracks and holes.

The chemicals were first sprayed onto the concrete lid surface and then scrubbed in by hand by the EET Technician. Chemical 100 was applied first to clean and prepare the surface and to encapsulate all loose surface contamination. The process of applying and scrubbing chemical 100 took 8 minutes; 22 ounces of chemical 100 was used. It was left on the lid surface overnight. A surface smear was taken the next day prior to rinsing off the chemical. The chemical was then rinsed off by pouring demineralized water on the surface and then hand scrubbing the surface. After the water was scrubbed into the concrete surface, it was vacuumed and another surface smear was taken. Following this first application, 11 ounces of chemical 300 was sprayed onto the surface, and rubbed in by hand. After chemical 300 was rubbed into the surface 11 ounces of chemical 200 was applied and also rubbed into the surface. These chemicals, which work together, were left on the surface for two hours and then rinsed off using the same method described above. After rinsing, another surface smear was taken. The smears showed that contamination levels were decreasing so another application of chemicals 200 and 300 was applied. Chemicals 200 and 300 are used to open the pores of the concrete and extract the contaminants. After the second application of chemicals 200 and 300 another application of chemical 100 was applied and left overnight to see if the remaining contamination could be removed. The following day, when the chemical 100 was removed, the level of contamination had gone down, so another application of chemicals 200 and 300 was 
applied to see if it could draw the remainder of the contamination out of the concrete lid. After letting the 200 and 300 chemicals dwell for two hours, they were rinsed off and a smear was taken on the lid surface which showed that the levels of contamination had gone up instead of down. From this data it was determined that another application of 100 was needed. Another application of chemical 100 was then applied and removed and a smear was taken. The levels of contamination dropped to the lowest level after the last application of chemical 100. In summary, the application of chemicals was as follows:

1) Chemical 100 was applied and left on overnight and then rinsed and vacuumed.

2) Chemicals 200 and 300 were applied and left to dwell 2 hours then rinsed and vacuumed.

3) Chemicals 200 and 300 were applied and left to dwell 2 hours then rinsed and vacuumed.

4) Chemical 100 was applied and left on overnight and then rinsed and vacuumed.

5) Chemicals 200 and 300 were applied and left to dwell 2 hours then rinsed and vacuumed.

6) Chemical 100 was applied and left to dwell for 2 hours then rinsed and vacuumed.

\subsection{Chemical Results}

EET's decontamination technique was very easy to use and took approximately 15 minutes of labor per application, including the time to apply and remove the chemical from the concrete lid. Chemicals dwell time varied from $2-24$ hours on the concrete lid. This technique could be used not only for flat, horizontal surfaces but for equipment, piping, and irregular and vertical surfaces as long as there is a way to scrub and vacuum the chemical off the surface. The chemical can either be sprayed or poured on the surface. After the chemical is applied to the surface, it gels which causes it to stay on the surface. Approximately 1 gallon of chemicals (which includes all three chemicals) was used during this demonstration and the total liquid waste generated was approximately 2.0 gallons, including the rinse water. The 2.0 gallons of liquid waste represented a much lower rate of secondary waste generation compared to current decontamination methods (i.e. detergents, water jet blasting).

Initial readings of the lid were $21,000 \mathrm{~d} / \mathrm{m}$ beta/gamma smearable, $147 \mathrm{~d} / \mathrm{m}$ alpha smearable, and $150 \mathrm{mr}$ beta/gamma contact. After the first application of 100 the contamination level had increased to such high levels that Radiation Engineering approval had to be given before work could continue. After rinsing, the surface of the lid was again surveyed and the contamination levels decreased to below initial readings. This indicated that there was more contamination under the surface of the concrete and the first application of 100 had extracted and encapsulated the contamination into the chemical.

EET's demonstration concluded after 3 applications of each chemicals 300,200 , and 100, with chemical 100 being applied last. After analyzing the results, it was assumed that the lid could be cleaned to free release levels with several more chemical applications. The results from the test are listed in Table 2. 
TABLE 2

EET Concrete Cleaning Results At ICPP

\begin{tabular}{|c|c|c|c|c|c|}
\hline : & SONTACT: & Conract: & SMEARABIE & SMARABLE & Reduction \\
\hline & BEFORE & AFTER & BEFORE & AFTER & \\
\hline \#1 & 150 & 100 & $\begin{array}{c}21,000 \beta / 1 / \gamma \\
147 \alpha\end{array}$ & $\begin{array}{c}540 \beta / \gamma \\
14 \alpha\end{array}$ & $\begin{array}{c}33.3 \% \\
\text { (Contact) }\end{array}$ \\
\hline $\begin{array}{l}\text { 1st application } \\
\text { of chemical } 100\end{array}$ & N/A & N/A & $\begin{array}{c}=213,000 \beta / Y \\
3,000 \alpha\end{array}$ & $\begin{array}{l}\text { After rinsing } \\
40,000 \beta / \gamma \\
40 \alpha\end{array}$ & \multirow{5}{*}{$\begin{array}{c}\text { Overall } \\
\text { Smearable } \\
97.4 \% \beta / \gamma \\
90.0 \% \alpha \\
\text { (Based on highest } \\
\text { readings) }\end{array}$} \\
\hline $\begin{array}{l}\text { 1st \& 2nd } \\
\text { application of } \\
\text { chemicals } 200 \\
\text { and } 300\end{array}$ & N/A & N/A & $\begin{array}{c}=40,000 \beta / \gamma \\
40 \alpha\end{array}$ & $\begin{array}{l}\text { After rinsing } \\
30,000 \beta / y \\
24 \alpha\end{array}$ & \\
\hline $\begin{array}{l}\text { 2nd application } \\
\text { of chemical } 100\end{array}$ & N/A & N/A & $\begin{array}{c}30,000 \beta / \gamma \\
24 \alpha\end{array}$ & $\begin{array}{c}\text { After rinsing } \\
1,200 \beta / y \\
20 \alpha\end{array}$ & \\
\hline $\begin{array}{l}\text { 3rd application } \\
\text { of chemicals } \\
200 \text { and } 300\end{array}$ & N/A & N/A & $=1,200 \beta / \gamma$ & $\begin{array}{c}\text { After rinsing } \\
5,000 \beta / \gamma \\
40 \alpha\end{array}$ & \\
\hline $\begin{array}{l}\text { 3rd application } \\
\text { of chemical } 100\end{array}$ & N/A & N/A & $\begin{array}{l}=5,000 \beta / \gamma \\
40 \alpha\end{array}$ & $\begin{array}{l}\text { After rinsing } \\
540 \beta / \gamma \\
14 \alpha\end{array}$ & \\
\hline
\end{tabular}

${ }^{*} \mathrm{~N} / \mathrm{A}=$ Not Available.

${ }^{\star}$ Results are after chemical application, but before removal.

Support (i.e. Rad Con Technicians, Equipment Operators) scheduling problems greatly increased the length of this demonstration. During the demonstration, the number of chemical applications was at times limited to one per day. The number of chemical application cycles per day would be dependent on the job size and scheduling. An average 4-8 application cycles (of each chemical) are used on projects where significant contamination levels are involved. Labor is the major cost in performing this cleaning technique.

Upon completion of the demonstration, the surface of the lid looked the same as at the start except for a small amount water staining and bleaching. There was no visible surface deterioration. 


\subsection{ELECTRO-OSMOTIC PULSE TECHNOLOGY}

Electrical/kinetic concrete decontamination techniques are a fairly new concept in concrete decontamination. These methods involve using an electrical field to cause contaminates to move through the concrete pores and then be deposited into a electrolyte solution. If electrical/kinetic decontamination is proven to be an effective decontamination method for removing all types of contamination, removing layers of concrete could be eliminated and the amount of chemicals normally used to decontaminate concrete could be reduced.

The Electro-Osmotic Pulse portion of this test was performed by Dry-Tec of North America. This technology removes contamination from concrete by setting up an electrical potential across the lid; copper coated steel rods are used as the cathodes and titanium bars as the anodes. When the electrical circuit is connected, a controlled cyclical voltage is applied to the system to cause osmotic migration of water from the anode to the cathode. As the moisture in the concrete is either pushed or pulled out of the concrete, contamination is also pushed or pulled through the concrete. This process was developed in Norway were it was installed in vaults, basements, and many other underground structures to prevent water from entering the structures. Dry-Tec's test at the ICPP was the first time this method had been tested to radiologically decontaminate concrete.

\subsection{Electro-Osmotic Pulse Equipment}

Dry-Tec's equipment consisted of two 4 feet $x 5$ feet fiberglass lined wooden boxes with five cooper coated steel rods located on the bottom of each box. The four anodes that were used on the wet test were 40 inches long $\times 1$ inch wide $\times 1 / 8$ inch thick titanium bars. The voltage and amperage was controlled by one $10 \mathrm{amp}$ central control unit.

\subsection{Electro-Osmotic Pulse Test Procedure}

The testing consisted of two different test set-ups with two lids. The tests ran simultaneously and were controlled by one central control unit. The tests were labeled wet and dry. The wet test consisted of putting the concrete lid into a wooden fiberglass lined pan with approximately 11 gallons of demineralized water and placing a small wooden ring filled with water on the top of the lid. The wooden ring was secured to the top of the lid with a caulking compound and the anodes (four connected titanium bars) were placed inside the wooden ring. The rebar eye lifts on the wet method were covered with a caulking compound. The dry method used the moisture already in the concrete. The concrete lid was placed into another pan filled with 11 gallons of demineralized water but no ring of water was placed on top. The anodes used for the dry method were the rebar lifting rings that were pre-cast into the concrete lid. The rebar eye lifts were sanded to remove as much rust as possible. Using the rebar eye lifts for the anodes had never been done before by Dry-Tec. The circuit was completed with a $110 \mathrm{~V}$ power source. A small positive and negative pulse was used to pull the moisture and contamination from the lids in each test. Figures 2 and 3 depict the general layout of both the dry and wet methods. 


\section{Dry Method}

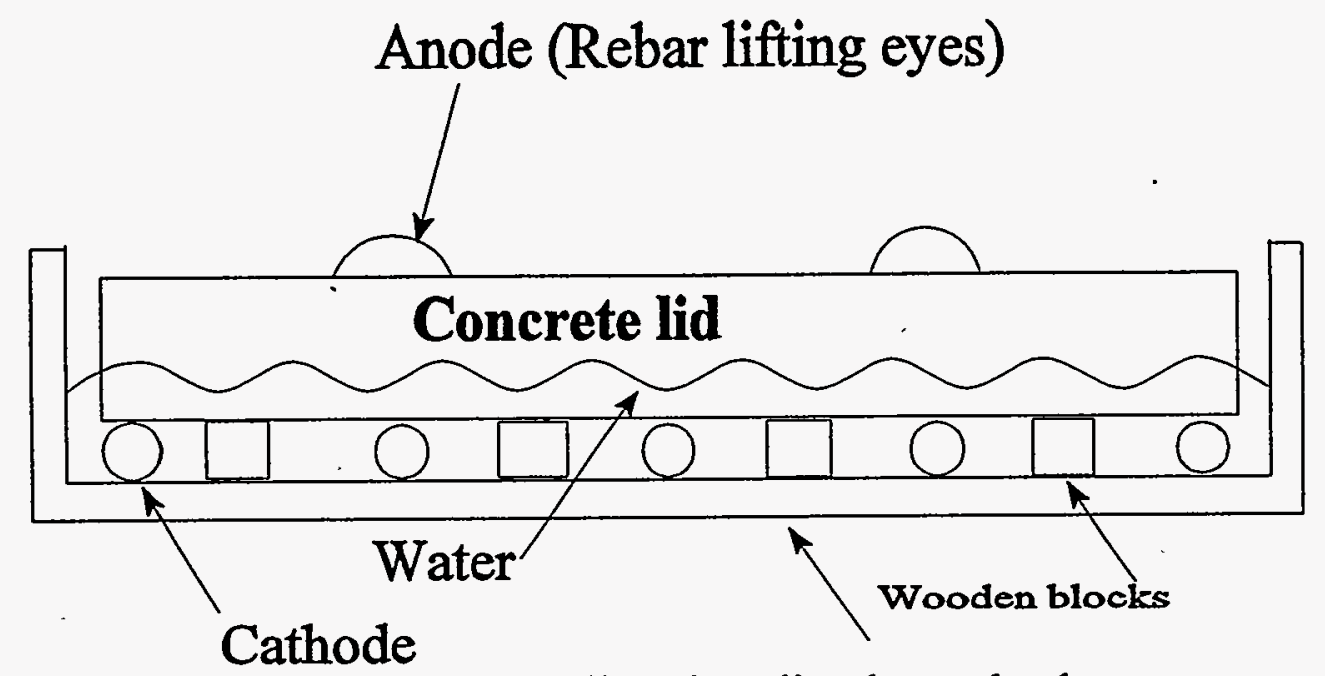

Fiberglass lined wooden box

Figure 2: Layout of Dry Method.

\section{Wet Method}

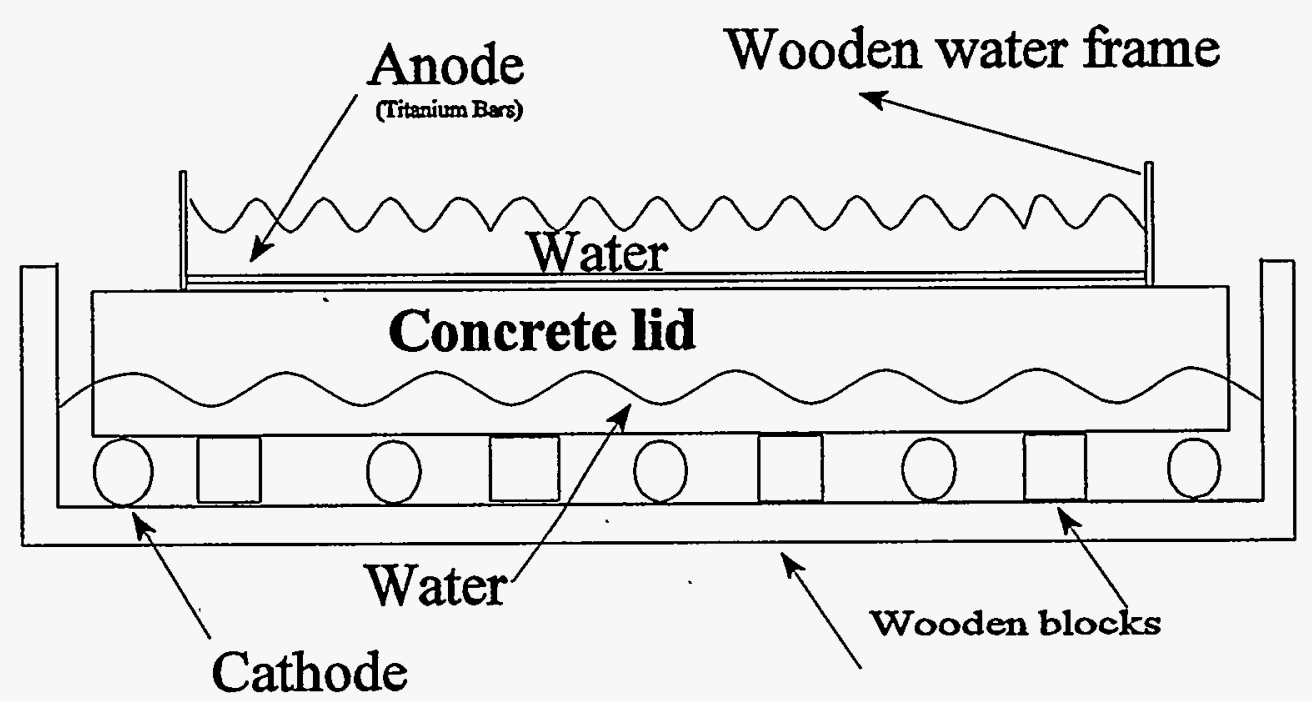

Fiberglass lined wooden box

Figure 3: Layout of Wet Method. 
When the lid for the wet method was unwrapped, no noticeable cracks or missing pieces of concrete were noticed. The lid used for the dry method was smooth but had a hole on one edge exposing the rebar located inside the concrete lid. Both of the lids had rust stains on the bottom side. Once surveys and core sample were taken, the hole in the one lid was patched with concrete and the holes where the core samples were taken were sealed with a silicone sealer. After the bottom surfaces were prepared by patching the exposed rebar and vacuuming the small pieces of concrete off the surface, the lids were turned over so that the top surfaces were exposed and the system was hooked up and power turned on.

\subsection{Electro-Osmotic Pulse Results}

This technique is a fairly easy system to install and requires very little labor to operate. The system is also very flexible and can be used to decontaminate concrete and to help keep concrete rooms, vaults, and basins dry. The normal installation for drying rooms, vaults, and other underground structures would use graphite probes and cable instead of copper cathodes and titanium anodes. The cleaning time for this system varies on the condition and type of concrete to be cleaned. This method takes a longer period of time to work than the two previous methods but, in general, has lower labor needs. The moisture content of the concrete and the type of concrete has a direct effect on how long it takes before results can be seen.

The lids were placed into the pans and left to soak in the water for approximately 48 hours before the system was turned on. This allowed any loose contamination on the lid to disperse into the water throughout the demonstration. The water was sampled to determine the amount of contamination that had gone into the water. The water was also sampled at the end of the demonstration after the water had been pumped into a plastic drum. Approximately 21 gallons of contaminated water was generated during this test. The results from the water sampling can be seen in Figures 4 and 5 . This information shows a general increase in the amount of contamination in the water. For all but the last reading, the water was not mixed prior to sampling although the samples were always taken from the same place. The final water samples indicated a total of $1.037 \times 10^{6} \mathrm{~d} / \mathrm{s}$ for dry and $2.362 \times 10^{6} \mathrm{~d} / \mathrm{s}$ for wet were removed.

The voltage and amperage were measured on a daily basis. The voltage at the start of the test measured at 39.6 volts. The amperage to the wet system measured at $265 \mathrm{~mA}$ and the dry system measured $1 \mathrm{amp}$. After the system had been operating for three weeks, the voltage measured 39.3 volts and the amperages on the wet and dry methods remained fairly constant. 


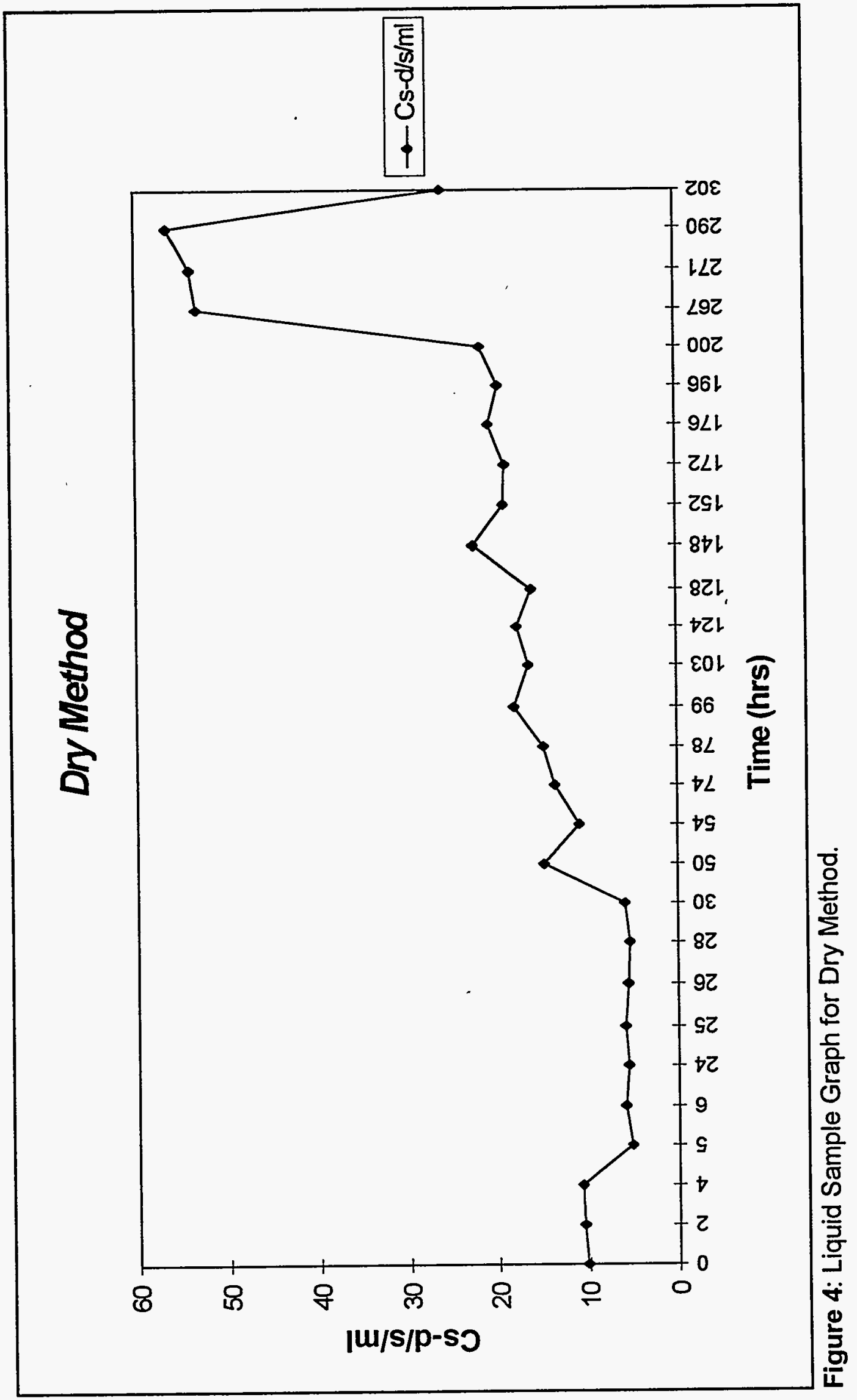

$\checkmark$ 


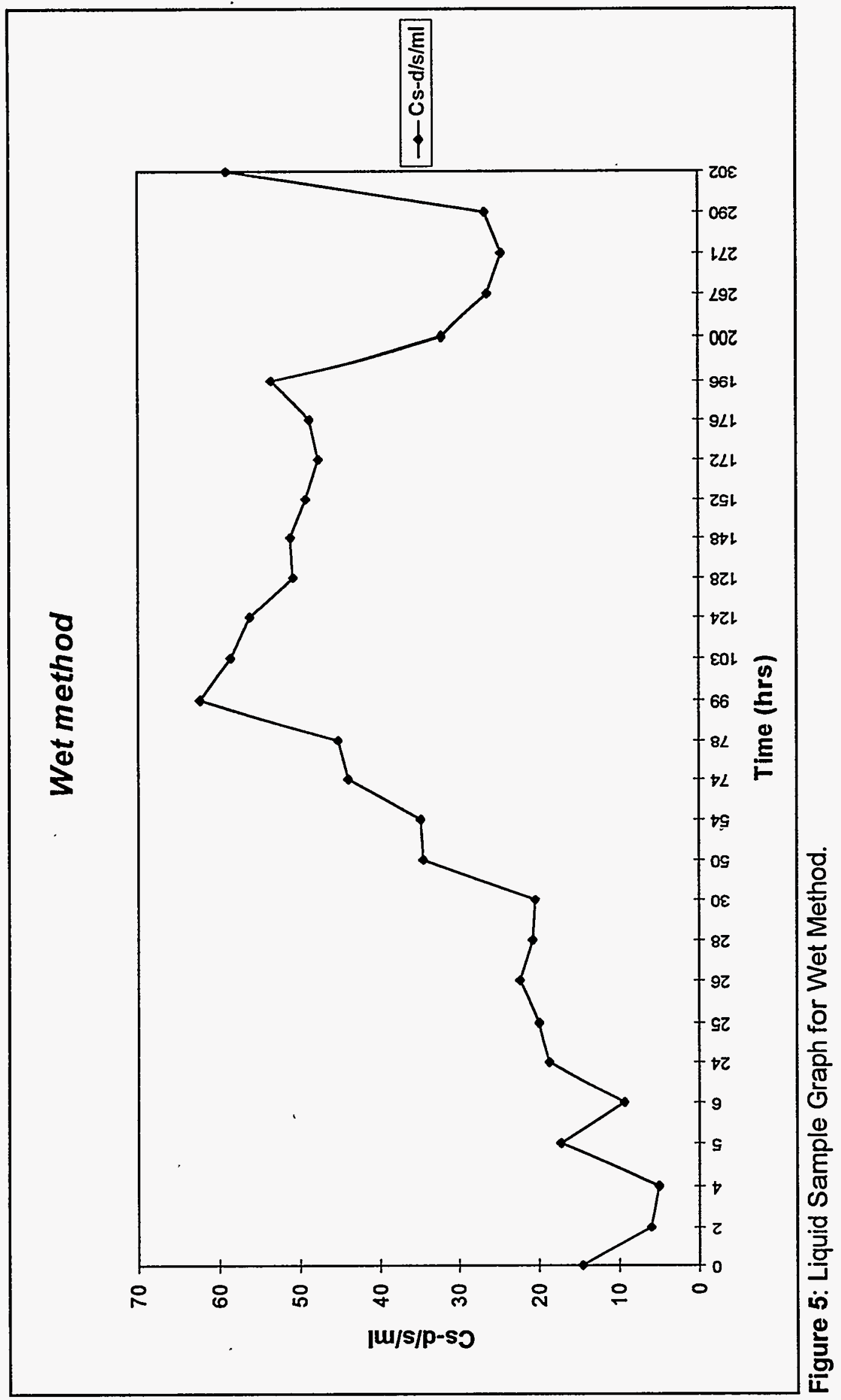


Initial and final radiological readings on the concrete lids can be see in Tables 3 and 4. These results indicate movement of contamination out of the concrete. The cathodes and pans were smeared and surveyed before and after the demonstration. The initial surveys and smears of the cathodes and pans showed no contamination on the pans or cathodes before they were put into the tent. The results from the smears and surveys of the cathodes and pans before and after the demonstration can be seen in Table 5. These also indicated movement of contamination out of the concrete.

\section{TABLE 3 \\ Dry-Tec (Wet Method) Concrete Cleaning Results At ICPP}

\begin{tabular}{|c|c|c|c|c|c|}
\hline ?.1. & (8) & (:) & SMEARABIIE & SMEARABLE & ? Reduction: \\
\hline & BEFORE & AFTER & BEFORE & AFTER & \\
\hline $\begin{array}{l}\text { Wet } \\
\text { Method }\end{array}$ & 150 & 30 & N/A & N/A & $\begin{array}{c}80 \% \\
\text { (Contact) }\end{array}$ \\
\hline (Area \#1) & N/A & N/A & $\begin{array}{c}16484 \beta / \gamma \\
44 \alpha\end{array}$ & $\begin{array}{c}10669 \beta / \gamma \\
35 \alpha\end{array}$ & $\begin{array}{c}35.3 \% \beta / \gamma \\
20.4 \% \alpha\end{array}$ \\
\hline (Area \#2) & $N / A$ & N/A & $\begin{array}{c}19969 \beta / \gamma \\
103 \alpha\end{array}$ & $\begin{array}{c}19366 \beta / \gamma \\
45 \alpha\end{array}$ & $\begin{array}{c}3 \% \beta \gamma \gamma \\
56.3 \% \alpha\end{array}$ \\
\hline (Area \#3) & N/A & N/A & $\begin{array}{c}17369 \beta / \gamma \\
44 \alpha\end{array}$ & $\begin{array}{c}20183 \beta / \gamma \\
68 \alpha\end{array}$ & $\begin{array}{c}\text { INCREASE } \\
16.2 \% \beta / Y \\
54.5 \% \alpha\end{array}$ \\
\hline (Area \#4) & N/A & N/A & $\begin{array}{c}17253 \beta / Y \\
66 \alpha\end{array}$ & $\begin{array}{c}13135 \beta / Y \\
35 \alpha\end{array}$ & $\begin{array}{c}23.8 \% \beta / Y \\
46.9 \% \alpha\end{array}$ \\
\hline
\end{tabular}


ग|q리료 $\forall$ ION $=\forall / N$.

\begin{tabular}{|c|c|c|c|c|}
\hline $\begin{array}{c}\text { DSZEL } \\
\text { Ay 000'6L }\end{array}$ & $\begin{array}{c}00 \\
1 \% 10\end{array}$ & $\forall / \mathbf{N}$ & 0 & sapoypeo אug \\
\hline $\begin{array}{c}1000 \varepsilon \downarrow \\
\lambda y 000^{\prime} 66\end{array}$ & $\begin{array}{r}00 \\
\text { ANO }\end{array}$ & s & 0 & ued Ka \\
\hline $\begin{array}{c}D \leftarrow 8 l \\
\Lambda / d ~ 000^{\prime} 0 \varepsilon\end{array}$ & $\begin{array}{c}00 \\
\text { xy } 0\end{array}$ & $\forall / N$ & 0 & sәрочце \\
\hline $\begin{array}{c}D \not L Z \\
A d^{000^{\prime} 09}\end{array}$ & $\begin{array}{c}\text { Do } \\
\text { ANO } 0\end{array}$ & Sl & 0 & ued IOM \\
\hline y $31 \pm \forall$ & 킹ㅋㅇ & 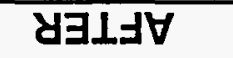 & 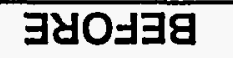 & \\
\hline 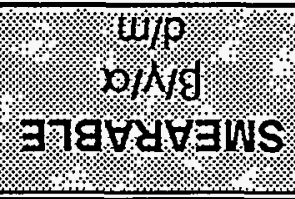 & 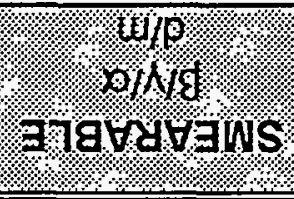 & 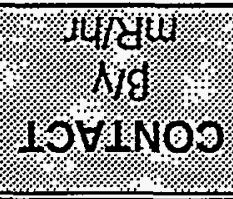 & 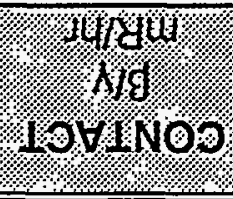 & \%\$ \\
\hline
\end{tabular}

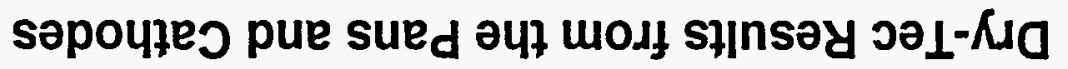
s $\exists 79 \forall 1$

\begin{tabular}{|c|c|c|c|c|c|}
\hline $\begin{array}{l}\% 0^{\circ} 69 \\
\text { NA } \% 6^{\circ} S\end{array}$ & $\begin{array}{c}0 S \varepsilon \\
\text { NS } s \varepsilon \downarrow \varepsilon \downarrow\end{array}$ & $\begin{array}{c}\text { D॰ll } \\
\text { NA } \varepsilon<6 \varepsilon b\end{array}$ & $\forall / N$ & $\forall / \mathbb{N}$ & (†\# еәд \\
\hline $\begin{array}{l}0 \% 0^{\circ} \angle 9 \\
\Lambda \gamma_{0} S^{\circ} \varepsilon\end{array}$ & $\begin{array}{c}062 \\
\text { Nd s9LLL }\end{array}$ & $\begin{array}{c}088 \\
\text { N/ } 9 \angle \mathrm{SLL}\end{array}$ & $\forall / N$ & $\forall / N$ & ( \\
\hline $\begin{array}{c}D \% 0^{\circ} \text { LS } \\
1 \% \sigma^{\circ} \% 9^{\circ} 8 \mathrm{C}\end{array}$ & $\begin{array}{c}\text { o } 2 \varepsilon \\
\text { No } \angle \varepsilon 66\end{array}$ & 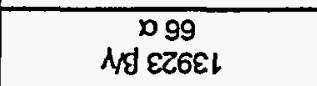 & $\forall / N$ & $\forall / N$ & (Z\# Еәd \\
\hline $\begin{array}{l}0 \% 9^{\circ} 0 t \\
1 / d \% 6^{\circ} L\end{array}$ & $\begin{array}{c}D S E \\
\text { I } 8 \angle 90 L\end{array}$ & $\begin{array}{c}069 \\
\text { Id 009Ll }\end{array}$ & $\forall / N$ & $\forall / N$ & ( \\
\hline \multirow[t]{2}{*}{$\begin{array}{l}\text { (1)equoj) } \\
\text { \%E8 }\end{array}$} & $\forall / N$ & $\forall / N$ & SZ & OSL & $\begin{array}{c}\text { poyjaw } \\
\text { no }\end{array}$ \\
\hline & yコدل & ヨy0ذચ9 & 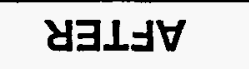 & 커에코 & \\
\hline 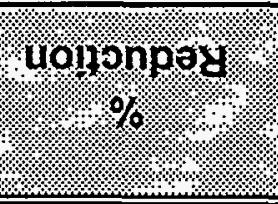 & 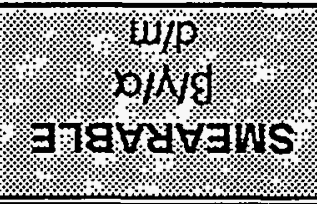 & 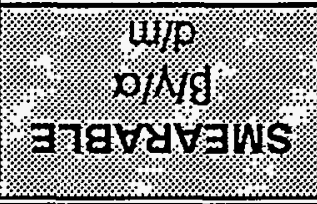 & 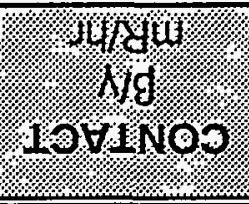 & \%ondu & 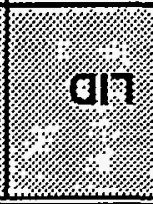 \\
\hline
\end{tabular}


After the demonstration was complete and the lids were turned over, small mounds of rust could be seen on the lids used for the dry method test. This indicated that the system was pulling the rust from the rebar to the surface of the concrete. A milky white substance was observed in the water of the dry method; this was later determined to be lime and cement from the lid. The water used in the wet method remained clear.

During this demonstration, water was added to the top of the wet method and to both pans because of evaporation that occurred during the process. Approximately 5 gallons was added to both pans and 4 gallons to the top pan on the wet method.

One important note for the dry method is that if this method is used on other structures that have rebar and they are used as anodes, applying a current to the rebar may cause the rebar to corrode. This needs futher investigation.

\subsection{RECOMMENDATION/CONCLUSIONS}

After reviewing the results of the concrete decontamination demonstration, it was evident that all three methods were effective at decontaminating concrete. The purpose of this demonstration was to evaulate three concrete cleaning methods and to determine how well each method performed. Each decontamination method could be used effectively to decontaminate concrete. However, several aspects would have to be investigated to allow choosing and using one method over the other two: type of concrete, location, condition of the concrete, and whether it was being cleaned for disposal or for reuse. Other factors to look at would include the kind of contamination on the concrete and the depth of the contamination. Listed below are some of the observations made during the demonstration.

Scabbling - This technique was the most labor intensive but was easy to use and very flexible. The surface removal rate was very fast when using this technique. When using the scabbling technique, the one thing to consider is the amount of concrete that needs to be removed. Removal of excessive amounts of concrete might effect structure integrity. The surface of the concrete will not be completely smooth, but will be even with no peaks or valleys. There are no liquid waste concerns. Also, being able to transfer the dust and debris into the drum as it is being removed is a great benefit.

Chemical - This technique was not very labor intensive but does involve hands-on application of the chemicals. When using these chemicals, the person applying this chemical may have to make several entries into the area to apply and remove the chemicals. This chemical technique will not destroy the substrate that is being cleaned. The chemicals proved that they can be used to decontaminate concrete while not producing as much secondary waste as the current methods being used (i.e. water jets, acids, detergents). It may be possible to develop remote techniques for applying the chemicals and scrubbing. 
Electro-Osmotic Pulse - This technique is not labor intensive and does not require much supervision. This is a slow process and the time it takes this system to decontaminate concrete will vary depending on the type of concrete, its condition and where it is located. The primary concern with this system is the amount of moisture that is in the concrete. This system has great potential and further testing would help define the best way to set up the system and its limitations.

The data from the core samples were inconsistent. The inconsistency within a core may have been due to cross contamination. The coring method of drilling to a certain depth and collecting the dust could easily cause cross contamination at the various core depths. It may be possible to avoid this problem by taking a five inch diameter core and then taking the core sample from the bottom of the large core. The total contamination in a core was also inconsistent. The data varied widely even for two cores taken at the same time within two inches of each other. This may have been because the contamination in the concrete was not uniformly dispersed. Therefore, the core information taken is not included in this report.

\subsection{REFERENCES}

1. Combs, A. B., Davis, W. P., Garner, J. M., and Geichman, J. R., " A Summary Review of Mound Facility's Experience in Decontamination of Concrete," Proceedings of the Concrete Decontamination Workshop, May 28-29, 1980. 